\title{
APPARENT QUALITY-OF-LIFE IN NATIONS How Long and Happy People Live
}

\author{
Ruut Veenhoven
}

Published in: Social Indicators Research 2005, vol 71, pp: 61-86

\begin{abstract}
Quality-of-life in nations can be measured by how long and happy people live. This is assessed by combining data on life expectancy drawn from civil registration with survey data on subjective enjoyment of life as a whole. This measure of 'apparent' quality-of-life is a good alternative to current indexes of 'assumed' quality-of-life such as the Human Development Index.

Data are available for 67 nations in the 1990s. The number of Happy-Life-Years varies considerably across nations. Switzerland is at the top with 63.0 years and Moldavia at the bottom with 20.5 years. China is in the middle with an average of 46.7. Happy lifetime has risen considerably in advanced nations over the last decade.

People live longer and happier in nations characterised by economic affluence, freedom and justice. Together these three societal qualities explain $66 \%$ of the cross-national variance in Happy-Life-Years. Income equality and generous social security do not appear to be required for a long and happy life.
\end{abstract}

Keywords: quality of life, happiness, life expectancy, happiness adjusted life years, crossnational

\section{INTRODUCTION}

When speaking about 'quality-of-life' in a nation we denote how well its citizens live. There are two ways to assess how well people live. One is to consider to what extent the country provides conditions deemed essential for a good life. In this approach the emphasis is on societal input. Since there is little certainty about what people really need, I call this 'presumed' quality-of-life. The other approach is to asses how well people thrive. In this approach the emphasis is on societal output'. I call this 'apparent' quality of life (Veenhoven 1996).

An analogy may illustrate this distinction: the case of 'fertility' of the soil. If we want to know whether a piece of land is well suited for growing grain, we can estimate the input that the soil provides or consider the output it has yielded earlier.

In the input approach, we consider the structure of the soil, its percentage of moisture, the minerals and nutrients it contains, etc., because we know fairly well what grain needs and to what conditions it can adapt, we can predict fairly accurately how well the grain will grow on that soil. 
In the output approach we consider the harvest. We then look at the quantity and quality of the grain harvested. Historically the fertility of land has been established in the latter way, that is, through experience (output).

The living conditions of grain can now be specified reasonably well, but the necessary living conditions for humans are less easy to specify. Not only are the humans more complicated and many-sided than grain they are also much more adaptable. In fact, a major biological specialization of the human species is its lack of specialism, combined with a capacity for learning. Therefore, the possible range of, and variation in livable societies for humans is far greater than the possible range of soils and variations in those soils that will support the fruitful growth of grain. Soil requirements for grain can be assessed experimentally, yet controlled experiments on humans and human societies are almost impossible and could not be supported ethically.

Let us keep this in mind and now consider current estimates of quality-of-life in nations.

\subsection{Input approach: 'presumed' quality-of-life}

Most measures of quality-of-life in nations assess presence of conditions such as material affluence, schooling, political freedom and social security. There are at least two problems with this approach:

The first problem is that the need for these inputs can be questioned. Consider the example of 'social security'. Do we really need compulsory income insurance? Though there is wide public support for such arrangements, it is doubtful that we really 'need' them.

The second problem in this approach is the assumption that more of such conditions makes life better. Let us consider the case of income. A minimum level of income is certainly required, but wealth seems to be subject to satiation. The human species developed in conditions we would characterize as 'poor' by present day standards, so we can apparently live without luxury.

The assumptions underlying current input indicators have little ground in sound theory about human needs. The assumptions about the good life are rather rooted in bad experience and in ideology. Present QOL indicators typically reflect Western memories of poverty and inequality. Positively they reflect Western Enlightened creed. I have discussed the weaknesses of this approach in more detail elsewhere (Veenhoven 1996, 2000a)

\subsection{Output approach: 'apparent' quality-of-life}

The flourishing of plants or animals in a given ecological environment is usually measured by their functioning as apparent in growth, adequacy of behavior and absence of disease. Can the flourishing of humans in a social environment be measured by the same criteria?

Human thriving also manifests physically, particularly in good health and a long life. Therefore, we can infer the quality-of-life in a nation from the health of its citizens, however, the flourishing of humans involves more than biological functioning alone. Unlike plants and animals, humans can reflect on themselves and their situation. The fit with environmental demands is therefore also reflected in their appraisal of life. As such we can also infer quality-of-life in a nation from the citizen's happiness

The two approaches to the measurement of quality-of-life in nations are summarized in scheme 1; the latter method is elaborated in this paper. 


\section{INDICATORS OF 'APPARENT' QUALITY-OF-LIFE IN NATIONS}

Inferring quality-of-life from the 'health' and 'happiness' of citizens in a country is less easy than it seems. What do these terms mean precisely? How can these matters be measured?

\subsection{Measures of health in nations}

As in the case of plants and animals, the flourishing of humans can be judged by looking at their bio-physiological functioning, in other words by their 'health'.

\subsubsection{Measures of physical health}

The analogy with how plants flourish applies best where only bio-physiological functioning is concerned; this is also called 'physical health'. The physical health of organisms can be defined in two ways: one by absence of disease or impairment, two by signs of good functioning, such as energy or resilience. The former aspect of bio-physiological functioning is referred to as 'negative health', the latter as 'positive health' (Seedhouse 1986). The less negative and the more positive the physical health of citizens, the better the quality-oflife in their country is apparently.

The incidence and severity of impairments and disease can give a measure negative of health. This sounds easier than it is. Medical statistics say more about medical consumption than about illness. The available figures on illness are typically limited to 'incidence' and do not give us any information regarding 'severity'. Moreover, medical statistics typically concern 'specific' health defects and mostly do not give an overview of the 'overall' health situation in a country. Some attempts have been made to characterize overall health in nations, but unfortunately these are as yet not sufficiently standardized to allow international comparison.

Positive health can be measured by performance tests and by subjective reports about feelings of health. The latter indicators typically concern overall health. Periodical health surveys are used to monitor health feelings in several Western nations. Though the items used are quite diverse, some allow international comparison in a sizable number of nations. At this moment the best source is the subjective health item in the World Values Survey.

Health can also be measured by longevity. The number of years people live is assessed on the basis of civil registration of birth and death. This is not a problem for the generations that have passed away, however, for the living we must do with estimates. Life 'expectancy' is estimated on the basis of observed survival rates in age-cohorts. Average length of life in a country is commonly expressed in 'life-expectancy' at birth.

A long life is not necessarily a healthy life. Life expectancy may be high in a nation' but average health low. Extra years may be bought at the cost of a lot of illness. Therefore, health in nations is also measured by the average number of years people live free from chronic illness. This is expressed in Disability Adjusted Life Years (DALY's). Data on this matter has recently become available for a lot of countries (WHO 2001 Annex Table 3).

\subsubsection{Measures of mental health}

Instead of focusing on 'bio-physiological' functioning, one can also consider the adequacy of 'socio-psychological' functioning. This is what commonly is referred to as 'mental health'. Like in the case of physical health, there is also a difference between 'negative' and 
'positive' mental health (Jahoda 1958) and again the quality-of-life in a nation is apparently better the less disturbed people are and the more positively they function.

There is nothing wrong with this idea, but there are great problems in its operationalization. It is not easy to establish who is mentally 'ill' or not. Cross-national comparison is hampered by differences in manifestations of psychological disturbance, as well as differences in what constitutes a definition of mental 'illness' and how it is registered. This limits the use of this indicator to countries, which are culturally very similar. The measurement of positive mental health is still in its infancy and doesn't allow any crossnational comparison at all.

\subsection{Measures of happiness in nations}

Next to mere 'functioning', the thriving of humans can also be inferred from their 'happiness'. Humans can comprehend their situation. Like other higher animals they experience affects. These affective appraisals are highly indicative for the quality-of-life. The biological function of these faculties is to lead the organism to the best-suited

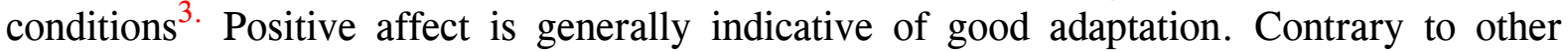
animals humans are also able to appraise their situation cognitively. Positive judgement of life is generally indicative of good adaptation.

The degree to which inhabitants of a nation feel happy can be assessed in different ways: indirectly by inferring from their behaviors and directly by asking how they feel about their life. Historically social scientists have preferred the former method. Today it is clear that only the latter is viable for this purpose.

\subsubsection{Behavioral manifestations}

Traditionally, the happiness of citizens in a nation was measured by the incidence of behaviors deemed indicative of despair. This approach does not require that people are fully aware of their malaise. Behavioral reactions can be affect driven or subconscious. Therefore, similar indicators are used for estimating the well-being in animals. Aggression, and self-mutilation and stereotypic behavior (i.e. pacing in a predetermined path back and forward by a caged lion) are often mentioned as indicative of despair in captive animals. Among wild animals migration can sometimes be seen as a way of escaping an increasingly inhostile environment. (i.e. the migration of game in response to the ruins in Africa)

\section{Despair}

Suicide rates are often used as an indicator of unhappiness in nations. This tradition dates back to Durkheim (1897). In this vein, the continuous rise of suicide in Western nations in the 20th century has been interpreted as showing that modernization reduces the quality-oflife.

There is probably some truth in the idea that general unhappiness gives rise to high suicide rates. Yet it is also clear that the incidence of suicide depends on many other things. In present day Western society, suicide rates may be rising because it is no longer taboo and because medical technology is used to postpone natural death. It is also possible that modern people are less willing to endure suffering. As in the case of other despair behaviors, these effects are not equally great in all societies at all times.

\section{Protest and desert}

Unhappiness is also seen to reflect in protest-behaviors, in purposeful political action (protest demonstrations, protest voting, etc) as well as in undirected rioting. In this line, the 
student revolts around 1970 have been interpreted as showing declining happiness in modern nations. Here again the problem is that these behaviors do not necessarily reflect personal dissatisfaction with life. One can be quite happy, but still be concerned about social injustice. Studies on participants in the 1960's-70's student rebellions illustrate this point (Keniston 1968). In fact, personal satisfaction may even facilitate engagement in social issues. Another thing, protests are typically concerned with specific aspects of society, and are therefore not very indicative of overall satisfaction with life.

Emigration seems more indicative of happiness in a nation, the decision to leave a country involves an overall evaluation of life in it. In this vein, Ziegler \& Britton (1981) showed that living conditions in emigration countries are typically poor. Yet, emigration may say more about opportunity to settle abroad than about the quality-of-life in the country, also, expectations about a better life elsewhere do not necessarily mean that the quality-of-life in one's home country is poor.

\subsubsection{Self-reports}

Though higher animals have the faculty of affective experience, they are typically unable to reflect on that experience and communicate it. We humans can. We can appraise how we feel about life and can communicate the estimate.

When we appraise how much we like the life we live, we seem to use two sources of information. We estimate our typical affective experience to asses how well we feel generally (hedonic level of affect) and at the cognitive level we compare 'life as it is' with standards of 'how life should be' (contentment). The former affective source of information seems generally more important than the latter cognitive one (Veenhoven 1991, 1995).

The word happiness is commonly used for these 'subtotals' and for the comprehensive appraisal. I use the terms 'overall' happiness or 'life-satisfaction' for the last judgement and refer to the affective and cognitive sub-appraisals respectively as 'hedonic level of affect' and 'contentment'. Elsewhere, these concepts are delineated in more detail (Veenhoven 1984: ch 2).

\section{Survey questions on happiness}

Happiness can be measured by self-report. Various questions have been developed for this purpose. All items and scales can be found in the 'Item bank' of the 'World Database of Happiness' (WDH 2003). The most commonly used item reads as follows:

Taking all together, how satisfied or dissatisfied are you currently with your life as a whole?

$\begin{array}{lllllllll}\text { Dissatisfied } & 2 & 3 & 4 & 5 & 6 & 7 & 8 & 9 \\ \text { Satisfied }\end{array}$

Since the 1970's, such questions have been included in many 'Quality-of-Life' surveys all over the world. There is now a growing body of data on happiness in nations. Presently there are comparable surveys in 67 nations. The data have been brought together in the 'World Database of Happiness'; section 'Distributional Findings in Nations' (WDH 2003).

\subsection{Measure of Happy-Life-Years}

Above we have seen that the best measure of health in nations is how long people live and that the best measure of happiness is self reported satisfaction with life-as-a-whole. Both measures are indicative of how well people thrive in a country, but neither of them captures this matter completely. One could at least imagine that people live long in a country but not 
happily, for instance because blind use of medical technology stretches out life and makes it too long. Likewise, one could imagine that people live happy in a country but not long, possibly as a result of too much indulgence.

That problem is solved when these measures are combined. Analogous to the measure of 'Disability Adjusted Life Years' mentioned above, one could compute 'Happiness Adjusted Life Years'. Below I will show how. I call this measure Happy-Life-Years (HLY).

\section{Computation}

The number of years citizens live happily in a country can be measured by combining information about length of life drawn from civil registrations of birth and death with data on overall appreciation of life as assessed in surveys. The following simple formula can be applied:

Happy-Life-Years = Life-expectancy at birth $\mathrm{x}$ 0-1 happiness

Suppose that life expectancy in a country is 50 years, and that the average score on a 0 to 10 -step happiness scale is 5 . Converted to a $0-1$ scale, the happiness score is then 0.5 . The product of 50 and 0.5 is 25 . So the number of happy life years is 25 in this country. If life expectancy is 80 years and average happiness 8 , the number of happy life years is $64(80 \mathrm{x}$ $0.8)$.

Theoretically, this indicator has a broad variation. The number of Happy Life Years is zero if nobody can live in a country, and infinity if society is ideal and its inhabitants immortal. The practical range will be between about 20 and 75 years. Presently at least, life expectancy at birth varies in nations between 30 and 80 , whereas average happiness is seldom lower than 0.4 on a 0 to 1 scale and seldom higher than 0.8 . The number of happyLife-Years will always be lower than standard life expectancy. It can equal real length of life only if everybody is perfectly happy in the country (score 1 on scale 0 to 1 ).

A high HLY means that citizens live both long and happily while a low HLY implies that the life of the average citizen is short and miserable. Medium HLY values can mean three things: 1) moderate length-of-lives and moderate appreciation-of-lives, 2) long but unhappy lives, and 3) short but happy lives.

In my opinion, this measure is the most comprehensive indicator of apparent quality of life in nations that we can have. The measure has also a clear meaning and appeals to common sense. Most people will agree that it is good to live long and happily. It is not for nothing that fairy tales end with sentiments like: they lived long and happy ever after.

I have described this indicator in more detail elsewhere (Veenhoven 1996, 2000). It scored highest in a scholarly review of quality-of-life indicators for national policy (Hagerty e.a. 2001).

\section{CROSS NATIONAL DIFFERENCES IN HAPPY-LIFE-YEARS}

Using this measure of Happy-Life-Years, we can now compare apparent quality of life in nations. Data on Happy-Life-Years in nations are published on the World Database of Happiness (WDH 2003). This continuous register of research on subjective enjoyment of 
life is updated regularly. Currently it provides data on 67 nations in the 1990s. These data are presented on appendix A. Scheme 2 presents some illustrative cases.

\section{TREND IN HAPPY-LIFE-YEARS}

Time series are available for a few nations, for the USA since 1948, for Japan since 1958 and for the first member states of the European Union since 1973. All these nations have witnessed a rise in the number of happy-life-years. This is mainly because life expectancy has been augmented in all these nations, but in several cases HLY has also been boosted by a rise in average happiness. The most spectacular case of this kind is Italy, where HLY has risen by 12 years since 1973 .

Scheme 3 presents the longest available time series, that of the USA 1948-1998. Americans have gained 7 Happy-Life-Years over these 50 years. Since average happiness has remained at the same level over this period, this rise in HLY is entirely due to a rise in life expectancy. In this case, the proportional rise in HLY illustrates that this rise in length of life was not gained at the cost of lower quality of life. If the extra years of life had been spent in misery, HLY would have lagged or could even have declined.

\section{SOCIETAL CORRELATES OF HAPPPY-LIFE-YEARS}

The next question is of course whether these differences in 'apparent' quality-of-life in nations have any correspondence with the earlier mentioned notions of 'assumed' qualityof-life. Is HLY higher in the nations that perform best on these standards?

To answer that question I inspected the statistical relationship between HLY and five societal qualities that are currently seen as required for a good life. These qualities are: 1) material wealth, 2) freedom, 3) social equality, 4) solidarity, and 5) justice. The indicators used for this purpose are enumerated in appendix B.

The analysis involves three steps: The first step is to assess how each of these societal characteristics relates to HLY, to do this I plotted scattergrams and computed zero-order correlations. Next I inspected to what degree the observed correlations could be attributed to differences in economic development across nations. To do this I computed partial correlations, controlling for wealth of the country. Lastly I looked at how much of the variance in HLY across nations could be explained by these societal characteristics together. An overview is presented in scheme 4. I will expand on the main findings below.

\section{$5.1 \quad$ Wealth}

Until recently, quality-of-life in nations was equated with material prosperity and measured by GDP per capita. It is now acknowledged that money is not everything, but wealth is still prominent in quality-of-life indexes such as the Human Development Index (UNPD 2001) and Estes' (1984) Index of Social Progress. How does this hallmark of 'assumed' qualityof-life relate to our measure of 'apparent' quality-of-life?

The relationship between income per head and HLY in nations is presented in scheme 5 . This scattergram shows a strong correspondence, the correlation coefficient is +.73 . This result fits the common assumption that wealth is essential to quality-of-life. Yet with a closer look one can see that there is a limit to the benefits of material wealth. In the 
scattergram one can recognize a curve of diminishing returns. The correlation is mainly in the left segment of the scattergram among nations with an income per capita below $\$$ 15.000. There is little correlation among the richer nations $(\mathrm{r}=+.18)$.

\subsection{Freedom}

Opinion about the blessings of freedom is mixed. Individualistic social philosophy assumes that people themselves know best what they need, and hence that they will thrive better if they can follow their own preferences. Conservatives doubt that people really know what is best for them and rather stress the wisdom of tradition and experts. Some schools of thought see different effects of different variants of freedom. Currently the New Right is quite positive about economic freedom, but at the same time it is critical about freedom in the private sphere of life. Free sex and the legalization of soft drugs are seen to as a threat to the quality-of-life. Likewise a common view in South-East Asia is that economic freedom will improve the human lot but that political freedom will not.

The relationship between political freedom and HLY is presented in scheme 6. Again we see a positive correlation, but the shape of the relationship is linear in this case, which suggests that freedom is not yet at its limit regarding its ability to confer quality-of-life. Similar patterns appear in the relationships of economic freedom and personal freedom to HLY. These findings support the liberal position. I have discussed this matter in more detail elsewhere (Veenhoven 1999, 2000b).

Free nations are typically also rich nations and hence the partial correlations in scheme 4 are considerably lower than the zero-order correlations. This could mean that the zeroorder correlations are largely spurious and that wealth is the main determinant of HLY. Yet is it also possible that freedom and wealth affect HLY equally much or that freedom affects HLY through its effects on the growth of wealth. Due to a lack of good time series data we cannot disentangle these effects as yet. For the time being, the partial correlations mark a minimum.

\subsection{Equality}

There is also a difference of opinion on the significance of social equality for the quality-oflife in nations. Egalitarians claim that social inequality is antithetical to quality-of-life, because it is morally unjust and because of its detrimental effects on self-respect and social bonds. Conservatives stress the positive functions of inequality and expect that enforced equality will go at the cost of quality-of-life. The discussion focuses very much on incomeequality.

The evidence is mixed in this case, since not all kinds of equality relate in the same way to HLY. Surprisingly there is no statistical association with income inequality. The scattergram on scheme 7 shows that people live equally long and happy in nations with small income disparities, such as Japan, as in nations with great income differences, such as Mexico. Statistical control for wealth of the nations even suggests a positive effect of income inequality.

The correlation with inequality between males and females is more in line with egalitarian supposition; HLY being higher in nations were women are least discriminated. Yet the partial correlation is quite small, which could mean that gender equality works out to be less beneficial after all.

HLY relates most strongly with difference in happiness as measured by its standard deviation and this correlation remains robust after control for wealth of the nation. Elsewhere I have argued that social inequality in nations cannot be measured inclusively by 
adding up differences in access to different matters and that the disparities in access to relevant resources (inputs) reflect best in the dispersion of happiness (output) See Veenhoven 2002. If I am right in this, these correlations mean that inequality still matters, though apparently not the specific inequalities that figure most prominently on the political agenda these days.

\subsection{Solidarity}

Next to freedom and equality, 'social solidarity' figured in the slogan of the French revolution (Liberté, egalité, fraternité), This and social solidarity is still seen as a prerequisite for a good life. In this analysis I considered two aspects of social solidarity in nations, one interpersonal respect and cooperation and two 'organized solidarity' in collective systems of social insurance.

The indicators of interpersonal solidarity relate positively to HLY. The strongest correlation is with 'tolerance' as measured by acceptance of minority group members as a neighbor. There is also a positive correlation with self-reported trust in compatriots and with activity in voluntary organizations. All these correlations are largely independent of the wealth of the nation.

The case of 'organized solidarity' is different however. The zero-order correlation between social security expenditures and HLY is positive, but control for the wealth of a nation reveals a negative relationship. I have investigated this matter in more detail elsewhere and found indeed that people are not happier and healthier in nations with lavish social security systems than in equally rich nations where the providential state is less openhanded (Veenhoven 2000c). Apparently we can live equally well in a residual welfare state. This finding illustrates that 'presumed' qualities of life do not always match 'apparent' quality-of-life.

\subsection{Justice}

Righteousness is also commonly mentioned as prerequisite for a good life. In this analysis I consider three indicators of justice in nations: rule of law, respect of civil liberties and prevalence of corruption. The relation between corruption and HLY is depicted in scheme 8 .

The scattergram reveals a strong negative relationship with this aspect of injustice. The other indicators of justice in nations are also strongly related to HLY. See scheme 4.

The partial correlations are also positive, but much smaller. As in the case of freedom this does not necessarily mean that the independent effect of justice is small, since the common variance of justice and wealth can be due to an effect of the former on the latter.

\subsection{Explained variance}

As a last step I considered how well these societal inputs predict the output of years lived happily. I limited that analysis to the variables for which we have at least 60 cases. This left me with wealth, economic freedom, political freedom, income inequality, rule of law and civil rights. Together these six societal qualities explain $66 \%$ of the variance in HLY in nations. Consideration of more variables in smaller nation sets yields $\mathrm{R}^{2}$ values of .85 and more. Dispersion of happiness in particular adds $13 \%$ explained variance. 


\section{DISCUSSION}

This correlation between HLY and common 'input' indicators shows that HLY measures something substantive and fits common sense notions of quality-of-life. Yet it also raises the question about its surplus value. If the two approaches to the measurement of quality-oflife in nations yield quite similar results, why then use this new output measure?

One reason is that not everything deemed required for a good life is really necessary. We saw this in the cases of income equality and social security. Secondly some of the things that are required today may loose relevance tomorrow. This is illustrated by the diminishing utility of wealth. Together this means that we better not focus on separate inputs, but rather measure final output.

Next there are practical reasons, HLY is more easily measured than current indexes of presumed quality-of-life and the concept of Happy-Life-Years is also easier to understand.

A look at appendix A shows that happiness and longevity tend to go together, in particular in the western countries where life if both long and happy. This raises the question whether we really need to combination of happiness and longevity. Why not simply suffice with the latter?

The answer is that happiness and longevity do not always parallel. People live rather short but fairly happy in $3^{\text {rd }}$ world countries like Bangladesh, India and Nigeria, while they live pretty long but unhappy in former $2^{\text {nd }}$ world nations such as Russia and Azerbaijan. Consequently the correlation is not high, $\mathrm{r}=+.38$. Hence the sum tells more than its constituents.

Still one can object that the same HLY score may denote different combinations of happiness and longevity. As noted earlier, a same medium score on HLY may reflect three combinations: 1) moderate longevity and medium happiness, 2) a long but unhappy life, and 3) a short but very happy life. These are indeed different situations, but still we may want to reduce this diversity to one dimension. In that case, HLY provides a way to do so. The combination makes sense, since both average happiness and longevity reflect how well people thrive in a country. In fact the combination of these two output measures makes more sense that the adding up of input indicators, such as income per head and education. I have elaborated that point elsewhere (Veenhoven 2000, section 4).

\section{CONCLUSION}

Quality-of-life in nations can be measured by the degree to which citizens life long and happily. The number of Happy-Life-Years differentiates well across nations and over time. This measure of 'apparent' quality-of-life is a good alternative to current indexes of 'assumed' quality-of-life such as the Human Development Index.

Application of this measure in the present day world shows that the quality-of-life is highest in nations characterised by economic affluence, freedom and justice. Income equality and generous social security do not appear to be required for a long and happy life. 


\section{REFERENCES}

Boelhouwer, J. \& Stoop, I. (1999)

Measuring well-being in the Netherlands

Social Indicators Research, vol. 48, pp. 51-75

Dijkstra, G. (2000)

A larger pie through a fair share? Gender equality and economic performance

Institute of Social Studies, Working Paper no. 315, The Hague, The Netherlands

Durkheim, E. (1897)

Le suicide: Etude de sociologie (Su icide, a sociological study)

Alcan, Paris.

Estes, R. (1984)

The social progress of nations

Preager, New York, USA

Hagerty, M., et. al. (2001)

Quality of Life indexes for national policy: Review and agenda for research

Social Indicators research, 2001, vol. 55, pp. 1-96.

Heritage Foundation (1999)

Index of economic freedom

Internet: www.heritage.org

ILO (1997)

The costs of social security: 15th international inquiry 1990-1993

International Labor Organization, Geneva, Switzerland

IMF (2000)

World Economic Outlook October 2000

International Monetary Fund, Washington, USA

Keniston, K (1968)

Young Radicals: Notes on committed youth

Harcourt, New York

Messick, R.E. (1996)

World survey of economic freedom 1995-96

Freedom House/ Transaction Publishers, London UK

Morris, W.N. (1992)

A functional analysis of the role of mood in affective systems.

In Clark, M.S. (ed.) 'Emotion' Review of personality and social psychology nr 13

Sage, New York.

Seedhouse, D (1986)

Health; the foundations for achievement

Wiley, Chichester UK

Transparency International

1995 TI Corruption Index

Press release, 15 June 1995, Transparency International, Berlin 
UN (1995)

Demographic Yearbook 1993

United Nations, New York

UNPD (1995)

Human Development Report 1995

United Nations Development Program, Oxford University Press, 1995, New York USA

UNPD (2001)

Human Development Report 2001

United Nations Development Program, Oxford University Press, 2001, New York USA

Veenhoven, R. (1984a)

Conditions of happiness

Reidel, Dordrecht

Veenhoven, R. (1991a)

Is happiness relative?

Social Indicators Research, vol. 24, pp. 1-34

Veenhoven, R. (1995b)

The cross-national pattern of happiness. Tests of predictions implied in three theories of happiness.

Social Indicators Research, vol. 34, pp. 33-68

Veenhoven, R. (1996b)

Happy Life-Expectancy: A Comprehensive Measure of Quality-of-life in Nations.

Social Indicators Research, 39, 1-58.

Veenhoven, R. (1999a)

Quality-of-life in Individualistic Society: A Comparison of 43 Nations in the Early 1990's.

Social Indicators Research, 48, 157-186.

Veenhoven, R. (2000c)

The Four Qualities of Life: Ordering Concepts and Measures of the Good Life.

Journal of Happiness Studies, 1-1,1-39.

Veenhoven, R. (2000a)

Freedom and happiness: a comparative study in 44 nations in the early 1990's

In: Diener, E. \& Suh, E.M. (Eds.) 'Culture and subjective wellbeing', MIT press, Cambridge, MA USA, 2000, ISBN 026204182 0, pp. 257-288

Veenhoven, R. (2000b)

Well-being in the welfare state: Level not higher, distribution not more equitable

Journal of Comparative Policy Analysis, 2000, vol.2, pp 91-125

Veenhoven, R. (2002a)

Return of inequality in modern society? Test by dispersion of life-satisfaction across time and nations

Paper presented at the ISA conference, Brisbane Australia July 2002

WHO (2001)

The World Health Report 2001

World Health Organization, Geneva, Switzerland 
WDH (2003)

World Database of Happiness. Continuous register of research on subjective appreciation of life. Version 2003

Erasmus University Rotterdam, Internet: http://www2.eur.nl/fsw/research/happiness

Ziegler, J.A. \& Britton, C.R. (1981)

A comparative analysis of socio-economic variations in measuring the quality of life

Social Science Quarterly, vol. 62, 303-312

\section{NOTES}

${ }^{1}$ Paper presented at the International conference 'Quality of Life in a Global World' Chinese University of Hong Kong, November 14 - 15, 2003. This paper builds on an earlier paper entitled 'Happy Life Expectancy' (Veenhoven 1996). The approach is summarized and new data are presented, now on 20 more nations and in time-trends.

2 This distinction between 'input' and 'output' has also been used to denote different levels of societal provisions, for instance government expenditures on housing as input and the number of rooms per capita as output (e.g. Boelhouwer \& Stoop, 1999: 53).

3 For a discussion of the adaptive functions of affect see Morris (1992). Affect has only developed in species that can choose how and where, to live such faculties would be of little use for plants. 


\section{Scheme 1}

Approaches to the measurement of quality-of-life in nations

Concept

\section{QUALITY-OF LIFE IN NATION}

Variants

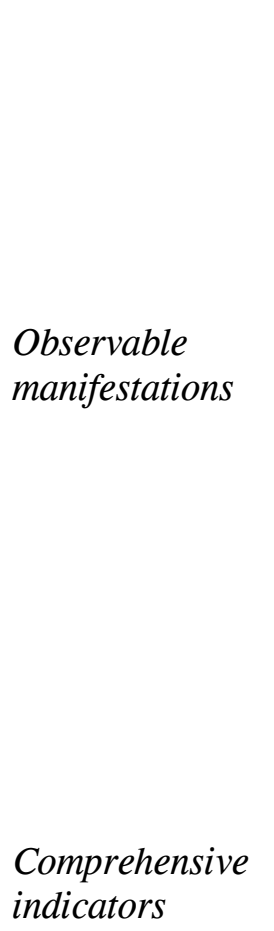

\section{Assumed}

Presence of conditions deemed essential for a good life, such as:

- Economic affluence f.e. GNP

- Political freedom f.e. Legal rights

- Social equality f.e. Income equality

- Access to knowledge f.e. Literacy rate

- Etc.....

Various sum-scores:

- Human Development Index

- Index of Social Progress

- Etc...
Apparent

Flourishing of citizens as apparent in:

- Good health

口 Physical

a Mental

- Happiness

\section{Happy Life Years}




\section{Scheme 2}

Happy-Life-Years in nations in the 1990s: some illustrative cases

\begin{tabular}{|l|c|l|c|l|c|}
\hline \multicolumn{2}{|c|}{$\begin{array}{c}\text { Top } \\
\text { > 58 years }\end{array}$} & \multicolumn{2}{c|}{$\begin{array}{c}\text { Middle range } \\
\pm \text { 4lyears }\end{array}$} & \multicolumn{2}{c|}{$\begin{array}{c}\text { Bottom } \\
<30 \text { years }\end{array}$} \\
\hline Switzerland & 63.0 & Philippines & 43.7 & Georgia & 29.7 \\
\hline Iceland & 61.8 & Greece & 41.4 & Russia & 27.8 \\
\hline Denmark & 59.9 & Turkey & 40.4 & Armenia & 26.2 \\
\hline Sweden & 59.9 & Hungary & 38.5 & Ukraine & 22.5 \\
\hline Ireland & 58.4 & Bolivia & 37.5 & Moldavia & 20.5 \\
\hline
\end{tabular}


Scheme 3

Happiness Adjusted Life Years in the USA 1948-1998

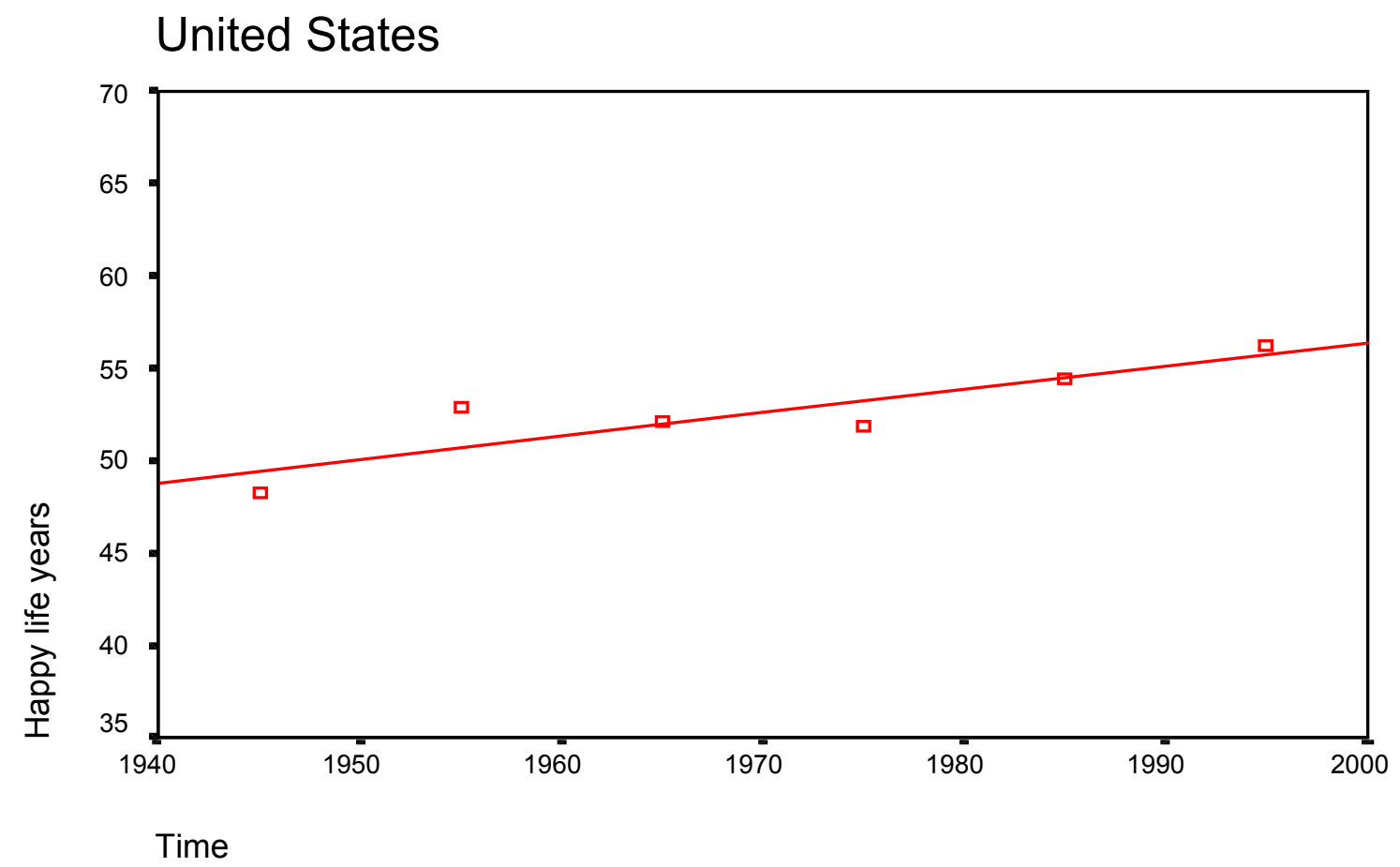


Scheme 4

Societal Qualities and Happy-Life-Years in 67 nations in the 1990s

\begin{tabular}{|c|c|c|c|}
\hline \multirow[t]{2}{*}{ Condition in nation } & \multicolumn{3}{|c|}{ Correlation with HLY } \\
\hline & Zero-order & $\begin{array}{c}\text { Wealth } \\
\text { Controlled }\end{array}$ & $N$ \\
\hline \multicolumn{4}{|l|}{ Wealth } \\
\hline - $\quad$ Purchasing power per head $*$ & +.73 & - & 66 \\
\hline \multicolumn{4}{|l|}{ Freedom } \\
\hline - Economic $*$ & +.71 & +.38 & 64 \\
\hline - $\quad$ Political * & +.53 & +.13 & 63 \\
\hline - $\quad$ Personal & +.61 & +.31 & 45 \\
\hline \multicolumn{4}{|l|}{ Equality } \\
\hline - Disparity in incomes * & -.10 & +.37 & 62 \\
\hline - Discrimination of women & -.46 & -.12 & 51 \\
\hline - Disparity in happiness & -.64 & -.37 & 54 \\
\hline \multicolumn{4}{|l|}{ Brotherhood } \\
\hline - $\quad$ Tolerance & +.72 & +.43 & 55 \\
\hline - Trust in compatriots & +.20 & +.20 & 37 \\
\hline - Voluntary work & +.40 & +.31 & 53 \\
\hline - Social security & +.34 & -.27 & 34 \\
\hline \multicolumn{4}{|l|}{ Justice } \\
\hline - $\quad$ Rule of law $*$ & +.65 & +.20 & 64 \\
\hline - $\quad$ Respect of civil rights * & +.60 & +.20 & 60 \\
\hline - Corruption & -.73 & -.32 & 40 \\
\hline Explained variance by variables marked with * & \multicolumn{2}{|c|}{$66 \%$} & 60 \\
\hline
\end{tabular}

Indicators described on appendix B 
Scheme 5

Wealth and Happy-Life-Years in 66 nations in the 1990s

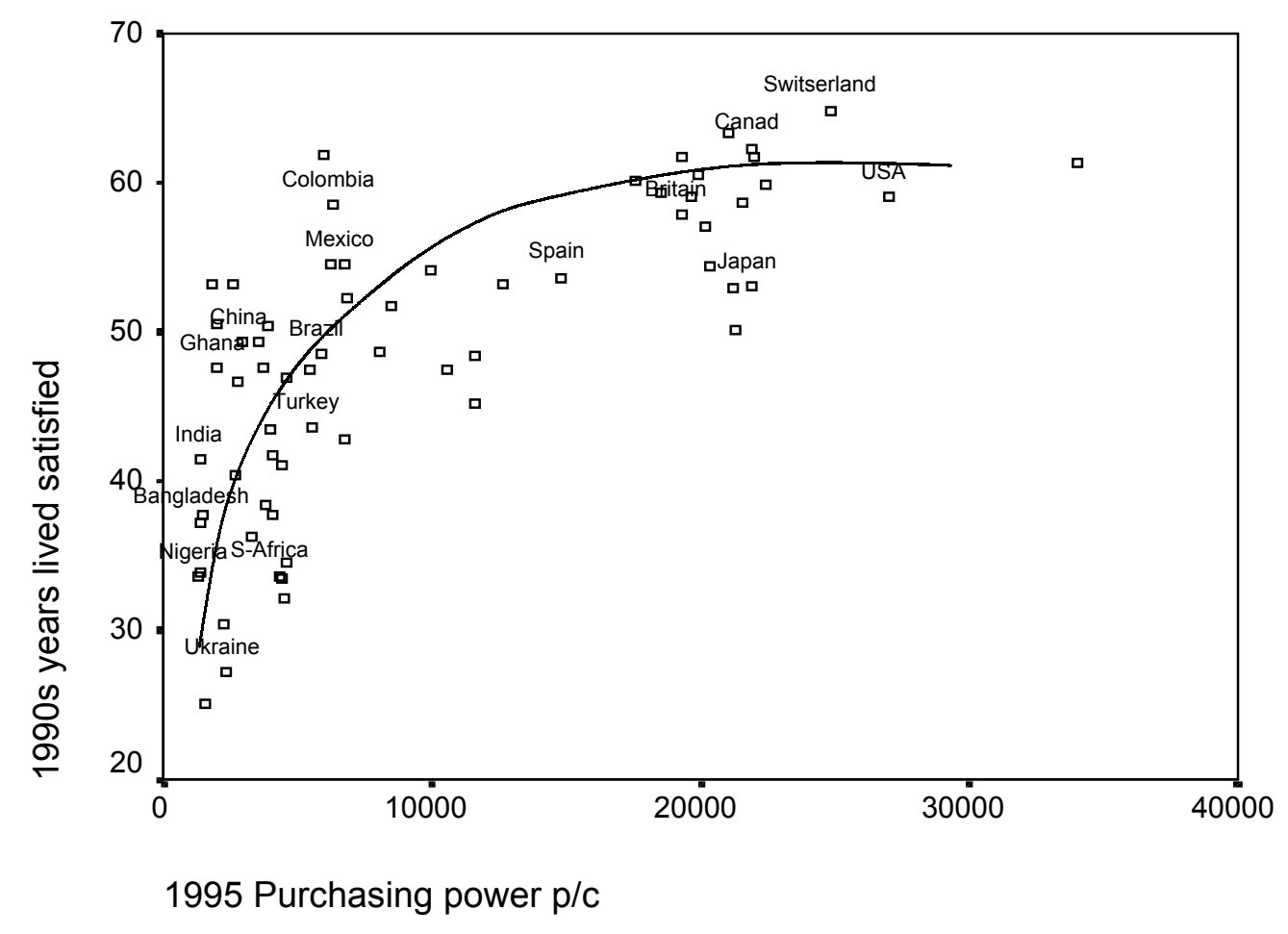




\section{Scheme 6}

Political freedom and Happy-Life-Years in 63 nations in the 1990s

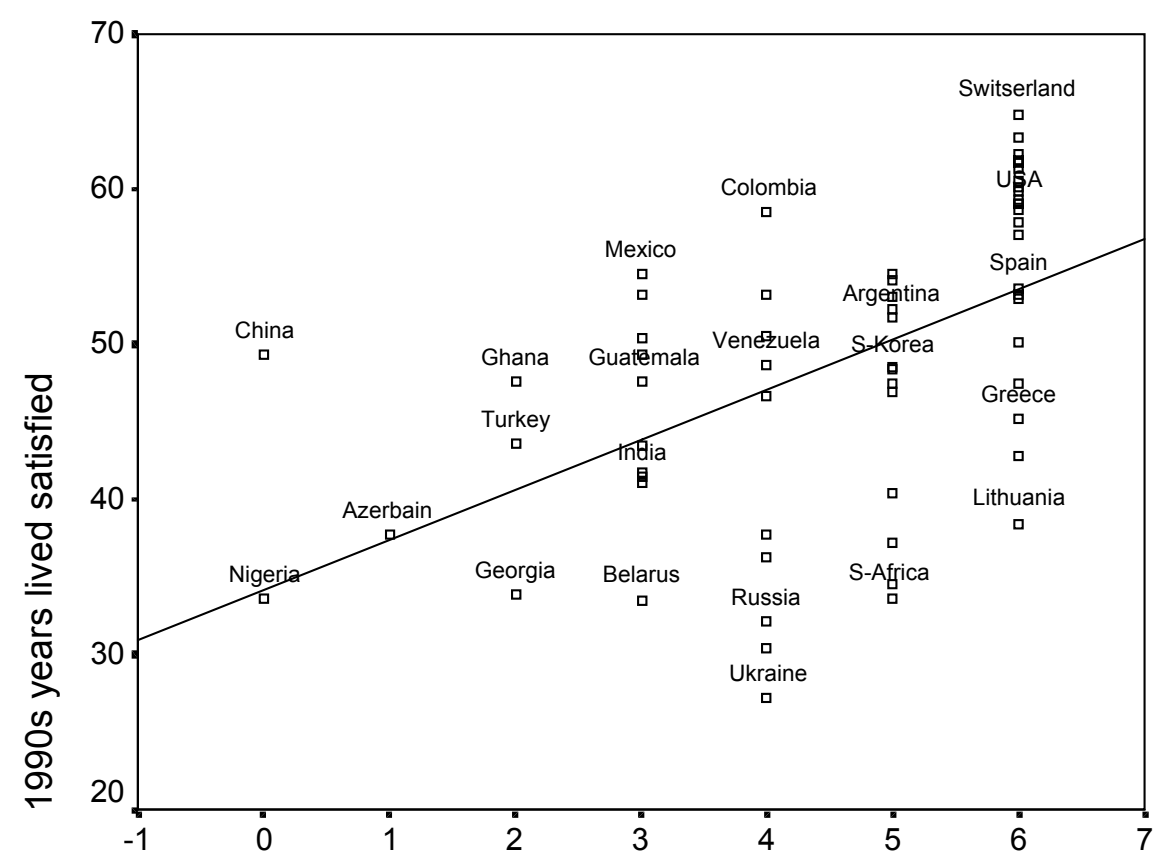

political freedom 


\section{Scheme 7}

Income Inequality and Happy-Life-Years in 62 nations in the 1990s

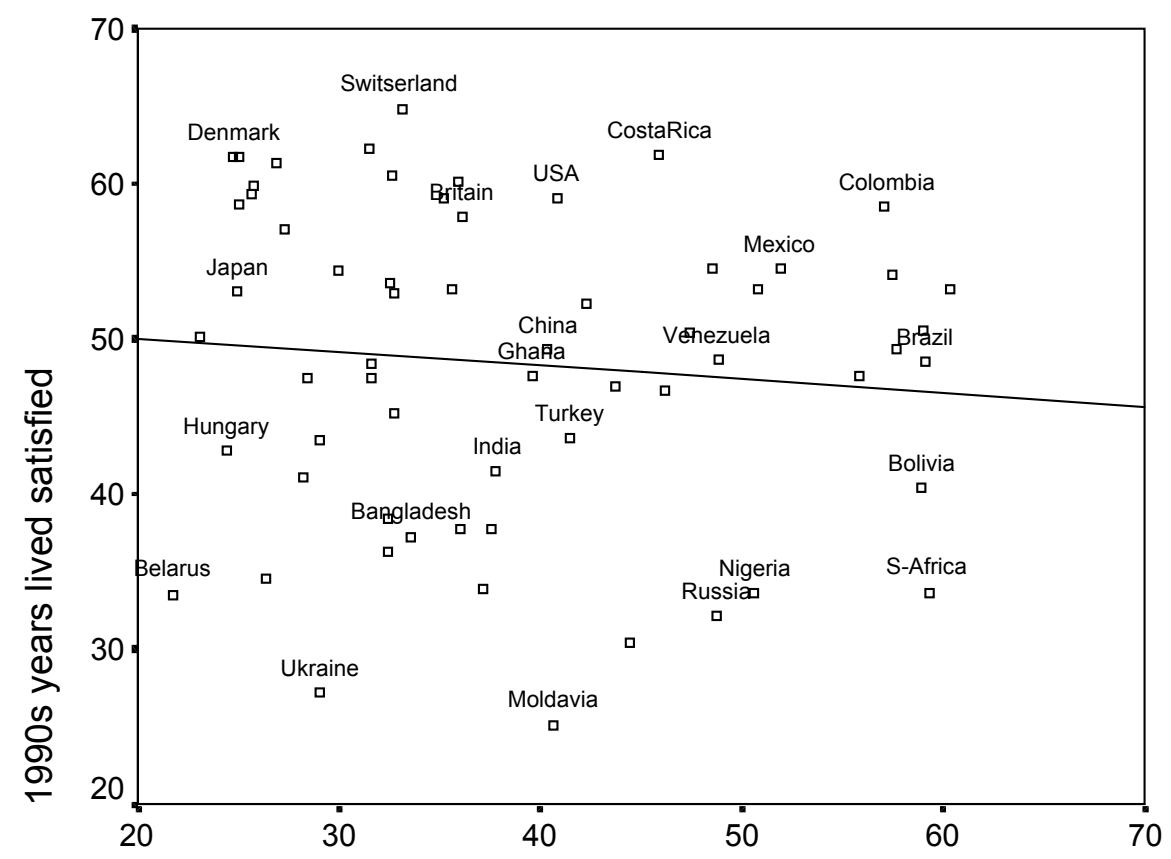

1990s Gini index: income inequlity 
Scheme 8

Corruption and Happy-Life-Years in 40 nations in the 1990s

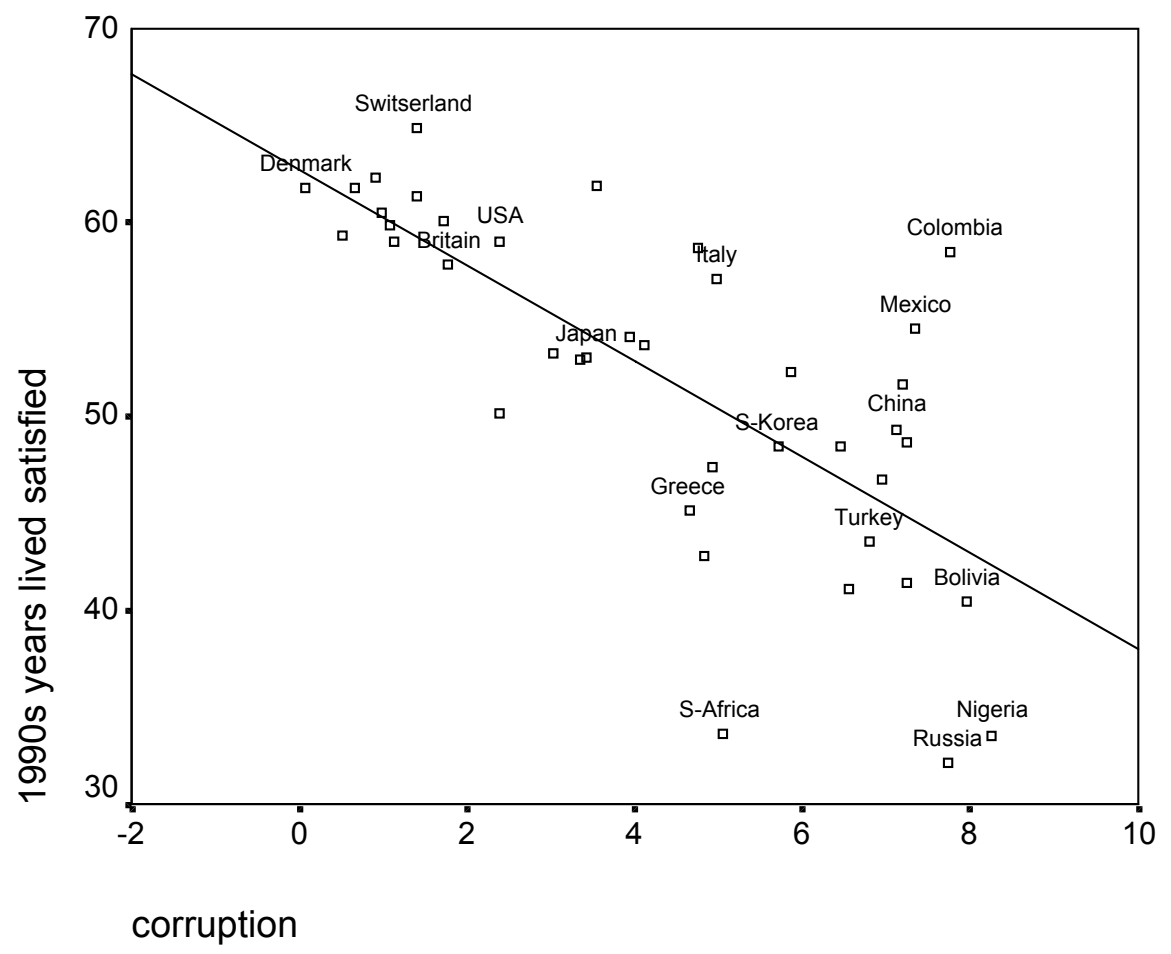


Appendix A

Apparent quality-of-life in 67 nations in the 1990s

\begin{tabular}{|c|c|c|c|}
\hline Nation & $\begin{array}{c}\text { Enjoyment } \\
\text { of life } 4 \\
\text { (scale } 0-1)\end{array}$ & $\begin{array}{l}\text { Length } \\
\text { of life } 5 \\
\text { (in years) }\end{array}$ & $\begin{array}{c}\text { Happy } \\
\text { Life Years }^{6}\end{array}$ \\
\hline Argentina & 6.8 & 72.6 & 49.1 \\
\hline Armenia & 3.7 & 70.9 & 26.2 \\
\hline Australia & 7.3 & 78.2 & 56.9 \\
\hline Austria & 6.1 & 76.7 & 47.0 \\
\hline Azerbaijan & 4.9 & 71.1 & 34.7 \\
\hline Bangladesh & 6.0 & 56.9 & 34.2 \\
\hline \begin{tabular}{|l|} 
Belarus \\
\end{tabular} & 4.4 & 69.3 & 30.3 \\
\hline Belgium & 7.3 & 76.9 & 56.4 \\
\hline \begin{tabular}{|l|} 
Bolivia \\
\end{tabular} & 6.2 & 60.5 & 37.5 \\
\hline Brazil & 7.0 & 66.6 & 46.3 \\
\hline Britain & 7.2 & 76.8 & 55.4 \\
\hline Bulgaria & 4.3 & 71.2 & 30.5 \\
\hline Canada & 7.7 & 79.1 & 60.6 \\
\hline Chile & 6.9 & 75.1 & 52.0 \\
\hline China & $6.7^{7}$ & 69.2 & 46.7 \\
\hline Colombia & $8.1^{7}$ & 70.3 & 57.1 \\
\hline Costa Rica & $7.9^{7}$ & 76.6 & 60.8 \\
\hline Croatia & 5.5 & 71.6 & 39.6 \\
\hline Czecho-Slovakia & 5.9 & 71.7 & 42.3 \\
\hline \begin{tabular}{|l|} 
Denmark \\
\end{tabular} & 8.0 & 75.3 & 59.9 \\
\hline Dominican Rep. & 6.8 & 70.3 & 47.9 \\
\hline Ecuador & 6.4 & 69.5 & 44.5 \\
\hline \begin{tabular}{|l|} 
El Salvador \\
\end{tabular} & 7.4 & 69.4 & 51.7 \\
\hline Estonia & 5.0 & 69.2 & 34.6 \\
\hline Finland & 7.5 & 76.4 & 57.1 \\
\hline \begin{tabular}{|l|} 
France \\
\end{tabular} & 6.4 & 78.7 & 50.5 \\
\hline Georgia & 4.1 & 73.2 & 29.7 \\
\hline Germany & 6.7 & 76.4 & 51.4 \\
\hline Ghana & $7.7^{7}$ & 57.0 & 43.9 \\
\hline Greece & 5.3 & 77.9 & 41.4 \\
\hline Guatemala & 7.2 & 66.1 & 47.3 \\
\hline Honduras & 7.0 & 68.8 & 48.0 \\
\hline Hungary & 5.6 & 68.9 & 38.6 \\
\hline Iceland & 7.8 & 79.2 & 61.8 \\
\hline India & 6.2 & 61.6 & 38.5 \\
\hline Ireland & 7.6 & 76.4 & 58.4 \\
\hline Italy & 7.0 & 78.0 & 54.6 \\
\hline Japan & 6.3 & 79.9 & 50.0 \\
\hline Latvia & 4.8 & 68.0 & 32.5 \\
\hline \begin{tabular}{|l|} 
Lithuania \\
\end{tabular} & 5.0 & 70.2 & 35.1 \\
\hline Luxembourg & 7.8 & 76.1 & 59.2 \\
\hline Macedonia & 5.2 & 71.9 & 37.6 \\
\hline Mexico & 7.3 & 72.1 & 52.5 \\
\hline Moldavia & 3.0 & 67.8 & 20.5 \\
\hline \begin{tabular}{|l|} 
Netherlands \\
\end{tabular} & 7.5 & 77.5 & 58.3 \\
\hline Nicaragua & 7.6 & 67.5 & 51.2 \\
\hline Nigeria & $6.3^{7}$ & 51.4 & 32.6 \\
\hline Norway & 7.4 & 77.6 & 57.5 \\
\hline
\end{tabular}




\begin{tabular}{|l|l|l|l|} 
Panama & 7.1 & 73.4 & $\mathbf{5 2 . 3}$ \\
\hline Paraguay & 6.8 & 69.1 & $\mathbf{4 6 . 7}$ \\
\hline Peru & 6.0 & 67.7 & $\mathbf{4 0 . 4}$ \\
\hline Philippines & 6.5 & 67.4 & $\mathbf{4 3 . 7}$ \\
\hline Poland & 6.2 & 71.1 & $\mathbf{4 3 . 8}$ \\
\hline Portugal & 6.7 & 74.8 & $\mathbf{5 0 . 5}$ \\
\hline Romania & 5.4 & 69.6 & $\mathbf{3 7 . 7}$ \\
\hline Russia & 4.2 & 65.5 & $\mathbf{2 7 . 8}$ \\
\hline South-Africa & 5.7 & 64.1 & $\mathbf{3 6 . 7}$ \\
\hline South-Korea & 6.3 & 71.7 & $\mathbf{4 5 . 3}$ \\
\hline Slovenia & 6.0 & 73.2 & $\mathbf{4 3 . 8}$ \\
\hline Spain & 6.5 & 77.7 & $\mathbf{5 0 . 8}$ \\
\hline Sweden & 7.6 & 78.4 & $\mathbf{5 9 . 9}$ \\
\hline Switzerland & 8.1 & 78.2 & $\mathbf{6 3 . 0}$ \\
\hline Turkey & 5.9 & 68.5 & $\mathbf{4 0 . 4}$ \\
\hline Ukraine & 3.3 & 68.5 & $\mathbf{2 2 . 5}$ \\
\hline Uruguay & 6.7 & 72.7 & $\mathbf{4 9 . 0}$ \\
\hline USA & 7.4 & 76.4 & $\mathbf{5 6 . 9}$ \\
\hline Venezuela & 6.4 & 72.3 & $\mathbf{4 6 . 0}$ \\
\hline
\end{tabular}

\section{Technical details}

4. Average enjoyment of life assessed using of surveys in general public samples. This list is based on responses to questions on life-satisfaction.

- Most scores are based on responses to the following question:

"All things considered, how satisfied or dissatisfied are you with your life-as-a-whole now? 1 dissatisfied 10 satisfied".

- This question is categorized as query type $122 \mathrm{C}$, sub-type O-SLW/c/sq/n/10/aa. This classification is explained in section $4 / 3$ of the introductory text.

- Scores on this 1-10 scale were transformed linearly to range $0-10$. This transformation in explained in the introductory text, chapter 7.3.

- Scores of most Latin American nations are based on responses to a somewhat different question.

"In general, would you say that you are satisfied with your life? Would you say that you are...very satisfied (4), quite satisfied (3), satisfied (2) or not very satisfied (1)?"

$\circ$ This question is categorized as query type $121 \mathrm{~B}$, subtype $\mathrm{O}-\mathrm{Slu} / \mathrm{c} / \mathrm{sq} / \mathrm{v} / 4 / \mathrm{b}$. This classification is explained in section $4 / 3$ of the introductory text.

- Scores on this 1-4 scale were transformed to range $0-10$ by means of expert weighing of response options. This 'Thurstone procedure' is explained in chapter $4 / 3$ of the introductory text.

- Since the above 1-10 questions have also been used in five of these Latin American nations, I could check whether this transformation yields comparable results. The transformed scores appeared to be slightly higher and were therefore corrected by subtracting 0.5 point.

- This combination of scores on two slightly different questions results in a list of 67 cases. The number of cases is smaller if one restricts to responses on identical questions. Restriction to a common question on 'happiness' (query type 111B) yields 60 cases and limitation to the above 1-10 life-satisfaction item (query type 1222C) 54 cases.

5. Life expectancy is estimated on the basis of civil registrations of birth and death. Source: Human Development Report 2001, table 1.

6. Computations: $0-1$ enjoyment of life multiplied by expected length of life

7. Life-satisfaction scores may be inflated in some countries, due to under sampling of rural population or inexperience with anonymous interviewing. Dubious cases are China, Colombia, Ghana and Nigeria are dubious cases. 


\section{Appendix B}

Characteristics of nations, used in correlational analysis

\begin{tabular}{|c|c|}
\hline \multicolumn{2}{|l|}{ Wealth } \\
\hline - Income & $\begin{array}{l}\text { Purchasing power per head in } 1995 \\
\text { Human Development Report 1999, table } 1 \text { (UNDP) }\end{array}$ \\
\hline \multicolumn{2}{|l|}{ Freedom } \\
\hline - Economic & $\begin{array}{l}\text { Index of economic freedom } 1999 . \\
\text { Heritage Foundation }\end{array}$ \\
\hline - Political & $\begin{array}{l}\text { Index of suppression of political rights 1994-95 (reversed) } \\
\text { Karantnycky et. al. } 1995\end{array}$ \\
\hline - Personal & $\begin{array}{l}\text { Index of freedom in personal life. Involves absence of } \\
\text { restrictions to traveling, religion, marriage, sex and suicide. } \\
\text { Both legal restrictions and public acceptance } \\
\text { Veenhoven } 2000 \mathrm{~b}\end{array}$ \\
\hline \multicolumn{2}{|l|}{ Equality } \\
\hline - Income equality & $\begin{array}{l}\text { Gini index } \\
\text { Human Development Report } 2001 \text { table } 12 \text { (UNDP) }\end{array}$ \\
\hline - Gender equality & $\begin{array}{l}\text { SIGE index of gender inequality. } \\
\text { Dijkstra } 2000\end{array}$ \\
\hline - Equality in happiness & $\begin{array}{l}\text { Standard deviation of life satisfaction. } \\
\text { Veenhoven } 2002\end{array}$ \\
\hline \multicolumn{2}{|l|}{ Solidarity } \\
\hline - Tolerance & $\begin{array}{l}\text { Responses to survey questions about the kind of people one } \\
\text { would like to have as a neighbor. } \\
\text { World Value Surveys 1990-1995, items 51-60 }\end{array}$ \\
\hline - Trust in compatriots & $\begin{array}{l}\text { Responses to survey question } \\
\text { World value Surveys } 1990-1995 \text {, item } 41\end{array}$ \\
\hline - Voluntary work & $\begin{array}{l}\text { Responses to survey questions } \\
\text { World value Surveys } 1990-1995 \text {, items } 28-35\end{array}$ \\
\hline - Social security & $\begin{array}{l}\text { Expenditures in percent of GDP } \\
\text { ILO } 1995\end{array}$ \\
\hline \multicolumn{2}{|l|}{ Justice } \\
\hline - Rule of law & $\begin{array}{l}\text { Index of Institutional Quality } 1997-98 \\
\text { IMF, World Economic Outlook October } 2000\end{array}$ \\
\hline - Violation of civil rights & $\begin{array}{l}\text { Index of suppression of civil rights 1994-95 } \\
\text { Karantnycky et. al. } 1995\end{array}$ \\
\hline - Corruption & $\begin{array}{l}\text { Rating by foreign businessmen and journalists } \\
\text { Transparency International }\end{array}$ \\
\hline
\end{tabular}

